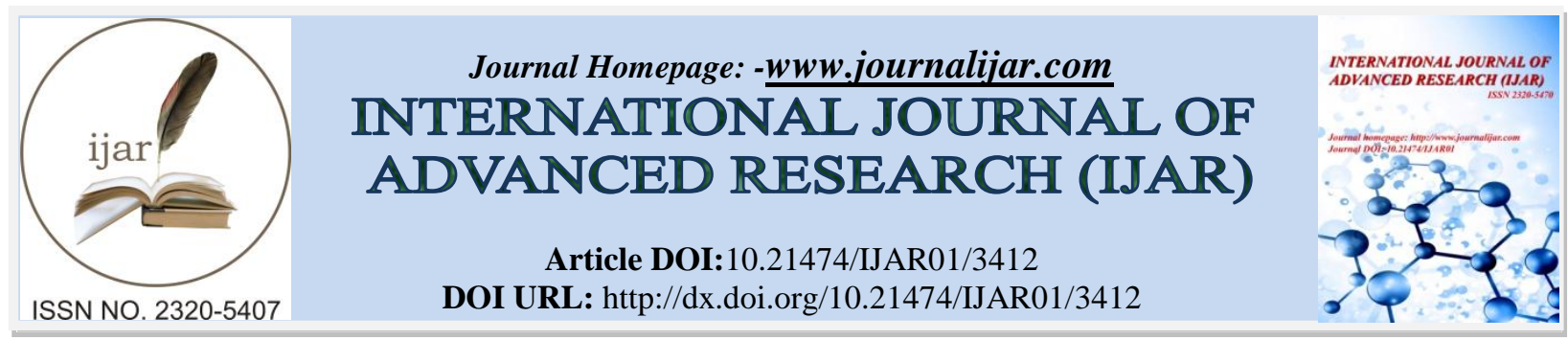

RESEARCH ARTICLE

\title{
REVIEW ON EMERGING POLLUTANTS AND ADVANCED OXIDATION PROCESSES.
}

\author{
Geasean J. Johnson ${ }^{1}$, Lendon A. Bullen ${ }^{1}$ and Mohamad Ridhuan bin Mohd Akil ${ }^{1}$. \\ ${ }^{1}$ UNEP- IESD, College of Environmental Science and Engineering, Tongji University, Shanghai 200092, PR China.
}

\section{Manuscript Info}

Manuscript History

Received: 11 December 2016

Final Accepted: 15 January 2017

Published: February 2017

Key words:-

Emerging pollutants, occurrence, pharmaceuticals, wastewater, emerging concern, toxicity, modeling, emerging contaminant (EC), endocrine disrupting compound (EDC), pharmaceuticals and personal care product (PPCP).

\begin{abstract}
Emerging pollutants are a modern day threat to water quality and security globally. These pollutants are largely as a result of pharmaceuticals and chemical compounds from personal care products that get washed through the sewerage system back into the environment. The long term effects of these compounds are not fully understood but have exhibited in some cases acute effects in aquatic flora and fauna. Science in many respects have caught up with rapid testing of water quality for these compounds however treatment processes in water works are lagging behind despite the many available method that effectively remove these compounds, namely advanced oxidation processes as reviewed.
\end{abstract}

Copy Right, IJAR, 2017,. All rights reserved.

\section{Introduction:-}

By 2025, 1800 million people will be living in countries or regions with absolute water scarcity and two thirds of the world population could be under stress conditions (UNDP, 2006). This figure may seem unbelievable but put in perspective the impending crisis is very much possible when one considers the fact that in 1900 the global population was two billion, this figure was exceeded to six billion in 2000 and is on a trajectory of nine billion by 2050. An ever increasing population is always a threat to the environmental sustainability and natural resources such as freshwater. Rising global populations and growing industries, advances in technology and medicine have resulted in the production of new chemical compounds more than ever beforein the history of the planet with many of their effects left unknown or slow to discovery. Modern day advances in rapid testing analytical instruments we are now able to detect once undetectable agents that pose a threat to the planet's dwindling water resource. Agents such as low concentrations of emerging contaminants in natural and drinking waters pose a real threat as they undermine water quality and have shown to have detrimental effects on aquatic biota as it was discovered that a significant amount of these compounds were present especially in surface water environment.

Water quality is a global issue. According to UN estimates, the world produces $1500 \mathrm{~km}^{3}$ of wastewater annually. That much waste or 'used' water represents more than six (6) times the volume of freshwater in all the world's rivers combined (UN WWAP, 2003). This becomes more worrisome and a threat to life as we know it when two and a half billion people have no means to proper sanitation (UNICEF, 2009) which means, a large volume of the waste produced goes untreated or improperly disposed. Seventy per cent of these people live in Asia. In china for example, with its rapid economic growth and urbanization, still $70 \%$ of its household wastewater goes untreated and end up in in the natural environment which means gallons of emerging contaminants are finding their way into the seas, rivers, aquifers and lakes. 
Emerging pollutants (EP/EC) are defined as any synthetic or naturally occurring chemical or organism that is not usually monitored in the environment with potentially known adverse ecological and human health effects (Czech

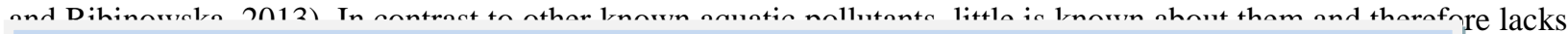

\section{Corresponding Author:- Geasean J. Johnson.}

(Barcelo and Kettrup, 2004; Burger and Moolan, 2006; Jiao and Cheng, 2008), and or negatively affect hormone synthesis and metabolism (Rice et al., 2003; Ying et al., 2004; Bradlow et al., 2005). Emergent pollutants that have adverse effects in ways like those mentioned are referred to as Endocrine Disrupting Compounds (EDCs) and have been characterized as a cause of reproductive disturbance in humans and wildlife (Hayes et al., 2002; Samir et al., 2006; Campbell et al., 2006).

\begin{tabular}{|l|l|l|l|l|}
\hline $\begin{array}{l}\text { Classes of Emerging } \\
\text { Contaminants }\end{array}$ & Major sub Classes & Sub-classes & Examples & Sources \\
\hline PPCPs & Pharmaceutical & Antiepileptic & $\begin{array}{l}\text { Carbamazapine, } \\
\text { primidone }\end{array}$ & WWTP \\
\cline { 3 - 5 } & & antibiotics & Roxithromycin & WWTP \\
\cline { 3 - 5 } & Antiseptic & Triclosan & WWTP \\
\cline { 3 - 5 } & anti-inflamatories & Ibuprofen & WWTP \\
\cline { 2 - 5 } & Personal care products & Polycyclic mucks & HHCB & WWTP \\
\cline { 3 - 5 } & $\begin{array}{l}\text { UV protection } \\
\text { screens }\end{array}$ & BP2 BP3 & WWTP \\
\cline { 2 - 5 } & Synthetic hormone & ethinylestradiol & & WWTP \\
\hline
\end{tabular}

Table 1:- Classification of emergent compound. 


\begin{tabular}{|c|c|c|c|c|}
\hline & & (EE2), DES & & \\
\hline \multirow[t]{6}{*}{ EDCs } & \multirow[t]{4}{*}{ Industrial compounds } & $\begin{array}{l}\text { Phenolic } \\
\text { compounds }\end{array}$ & sufacants & WWTP, run off \\
\hline & & phthalates & (DEP,DBP, DMPs) & WWTP, run off \\
\hline & & Fire retardants & $\begin{array}{l}\text { Brominated fire } \\
\text { retardants }\end{array}$ & $\begin{array}{l}\text { textile, paint, } \\
\text { fabric industry }\end{array}$ \\
\hline & & PCBs & & steel industry \\
\hline & Harmones & atural and synthetic & estrone & \\
\hline & Heavy metals & & $\begin{array}{l}\text { mercury, cadmium, } \\
\text { lead }\end{array}$ & $\begin{array}{l}\text { mining and } \\
\text { mettalurgy }\end{array}$ \\
\hline \multirow[t]{6}{*}{ Pesticides } & Organochlorine & & Aldrin & agricultural run off \\
\hline & Organophosphate & & ethion & agricultural run off \\
\hline & Cabamate & & Benomyl & agricultural run off \\
\hline & Triazines & & $\begin{array}{l}\text { Simazine, } \\
\text { cyanazine }\end{array}$ & agricultural run off \\
\hline & Pyrethroids & & bifenthrin & agricultural run off \\
\hline & $\begin{array}{l}\text { Chlorophenoxy } \\
\text { Herbicides }\end{array}$ & & triclopyr & agricultural run off \\
\hline
\end{tabular}

The main issue with these emergent compounds is that they have the ability to pass through conventional wastewater treatment plants without detection and removal. There is therefore an urgent need to build on present scientific knowledge and to create technologies that are adequately able to detect and monitor these pollutants as well as to remove them from waste water systems efficiently and economically. The first report of pharmaceuticals in wastewater treatment plant was published by Hignite and Azarnoff, 1977. Since then there has been an upward trend in the research of emergent contaminants, their effects, detection and classification in water science and management. Sauve and Desrosiers, (2014), in a review of emergent contaminants introduced three broad definitions of how these pollutants may be considered. Emergent contaminants, by the French scientists, were explained as pollutants that appeared only recently due to an increase in new chemicals such as pharmaceuticals and personal care products, pollutants that have been in the natural system for a period of time but has recently raised concerns or a new perspectives of the concerns of known contaminant. For this review three (3) pharmaceuticals and their occurrence and fate in the environment were discussed. Table 1 outlines the major classifications of ECs with examples. The review also discusses recent studies on advanced water treatment methods that have been proven to effectively degrade ECs.

Emergent pollutants enter water ways as most pollutants do, through point or non-point sources as depicted in the schematic diagram, fig 1 One of the most prevalent sources has been waste water treatment plants (Huang et al., 2003). This is because of the surreptitious nature of the compounds that allows them to pass through unnoticed and untreated by conventional treatment methods (Muller et al., 2010; Petrovic et al., 2013; Czajka and Londry, 2016). Since this discovery researchers have been in earnest to develop effective methods to remove these harmful compounds from waste water treatment plants so as to prevent them from getting into the environment. Bolong et al., (2009) reviews some of these advanced methods in details some of which will be explored in later sections of this review.

There have been an assortment of methodologies used to determine the presence and quantity of these emerging pollutants in various biological environments/matrices which have allowed researchers to fully grasp the persistence, quantity and quality of these active agents in natural and manmade systems. Psychotic drugs have been screened from matrices such as blood and urine using GC-MS and LC-MS methods. (Subramanian et al., 2008). Vanderford and Synder (2006) identified the anxiolytic drug, meprobamate in treated and untreated surface water sources by applying LC-MS/Ms. With applied HPLC-MC/MS, Reh et al., (2013) were able to obtain the quantity of forty four organic micro pollutants (OMP) in groundwater in parts of Germany. Some of these trace pollutants tend to be more persistent than others in the environment and may be found in various concentrations depending on the media and other factors. 


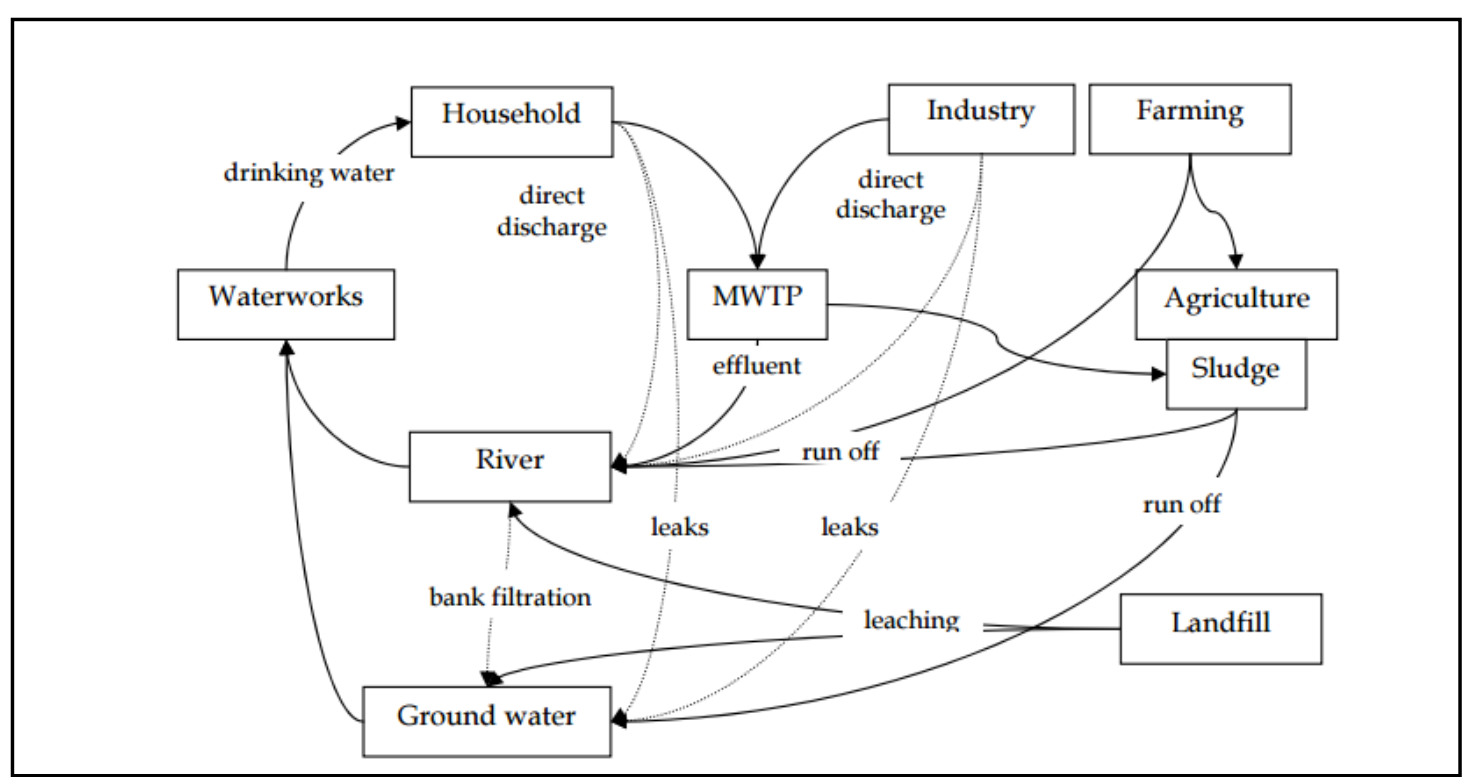

Fig 1: schematic diagram showing the flow of ECs into different system and media.

The Effects of Emerging Pollutants:-

The science around the effects of these surreptitious chemical compounds is not as conclusive as one might imagine, as such there is much need for more research geared towards investigating the toxicity of emerging contaminants such as pharmaceuticals and personal care products (PPCPs) in the aquatic environment. Pharmaceuticals, medicinal drugs, are purposefully designed to be effective in target hosts, in relatively small dosage, for human or animal treatment. This may explain largely why these compounds are found in miniscule quantities in various media when compared to other chemical pollutants. The threats of these compounds or rather the threats of their activate ingredients on non-target species still elude scientists and is feared that the possible subtle and gradual effects caused by the contaminants may be misunderstood as natural changes and therefore go undetected or undetectable. The presence of multiple pharmaceuticals in the environment also raises the question of joint toxicity which would result in a high toxic effect (Kortenkamp et al., 2007). The presence of antibiotic compounds in wastewater and water may also give rise to resistant microbes as Guardabassi et al., 2002; Miranda and Castillo, 1998 suggest. Data on the cause of certain cancers have indicated that these kinds of compounds can be assimilated by humans into tissues and can easily pass though cell membranes and avoid detection of the body to carry out designed physiological effects.

Pascoe et al., (2002) in a published study investigated the toxicity of 10 drugs, ibuprofen, paracetamol, acetylsalicylic acid, amoxicillin, bedroflumethiazide, furosemide, atenolol, diazepam, digoxin and amlodipine using cnidarian Hydra vulgaris. The investigation revealed that the substances did not have any acute toxicity to the organism at concentration up to $1.0 \mathrm{mgL}^{-1}$, however, three of the drugs did in fact have some retardation effect on polyp regeneration at $10 \mathrm{ugL}^{-1}$. These drugs were diazepam, digoxin and amlodipine. Lange et al., (2001) reported on the adverse effect of EE2 on fish which resulted in a feminizing effect. According to Kidd et al., (2007), an affect like that may result in population crash. Pharmaceuticals and personal care products may affect organisms in various ways, it is therefore the daunting task of figuring out how the compounds individually or jointly may adversely affect the systems of aquatic animals. A widely studied effect is the disruption of the endocrine system where these pollutants interfere the production, transport and balance of hormones necessary for growth, development and species to species interaction, see table 2 .

Table 2: EDC and documented effects. 


\begin{tabular}{|l|l|}
\hline Endocrine Disrupting Compounds & Health effects \\
\hline $\begin{array}{l}\text { Bisphenol A (BPA)Bisphenol A (BPA) - used } \\
\text { in epoxy and } \\
\text { polycarbonate plastics (in food and drink } \\
\text { packaging) - used in epoxy resin and }\end{array}$ & $\begin{array}{l}\text { Proven to have estrogenic effects in rats and hormonal } \\
\text { effects which increase breast cancer risk in human } \\
\text { Reported to act as anti-androgen that causes feminising }\end{array}$ \\
\hline $\begin{array}{l}\text { Estrone and 17- } \beta \text { estradiol (steroidal estrogens) } \\
\text { and }\end{array}$ & Cause feminization which observed for fish in sewage treatment \\
$\begin{array}{l}17-\alpha \text { ethynylestradiol (synthetic contraceptive) - } \\
\text { contained in contraceptive pills }\end{array}$ & \\
\hline $\begin{array}{l}\text { Antibiotics (such as penicillin, sulfonamides, } \\
\text { tetracylines) }\end{array}$ & $\begin{array}{l}\text { Shown to cause resistance among bacterial pathogens, } \\
\text { that lead to altered microbial community structure in the }\end{array}$ \\
\hline $\begin{array}{l}\text { Polychlorinated biphenyls (PCBs) — used } \\
\text { in electrical equipment (capacitors and } \\
\text { transformers) }\end{array}$ & $\begin{array}{l}\text { nature and affect higher food chain } \\
\text { The metabolites able to mimic estradiol (female hormone) } \\
\text { and cause carcinogenic. }\end{array}$ \\
\hline
\end{tabular}

\section{Florfenicol and Thiamphenicol:-}

Florfenicol and Thiamphenicol are anti biotics used commonly to treat animals and used as chemotherapy drugs to control diseases. They are both often used to treat livestock and aquatic species with infections such as pneumonia in cattle, and furunculosis in salmon. These drugs like most emerging contaminants, end up in the environment through excrement, having been metabolized in the animal. Both drugs are a part of a larger group of phenicols called Chloramphenicol which in many countries are banned in agriculture due to its serious side effects on humans. The chemical names for Florfenicol and thiamphenical are Acetamide, 2,2-dichloro-N-[1-(flouromethyl)-2- hydroxy-2[4-(methylsulfonyl)phenyl]ethyl]-[R-( $\left.\left.\mathrm{R}^{*}, \mathrm{~S}^{*}\right)\right]$ - $\quad$ and 2,2-dichloro-N-[(1R,2R)-1,3-dihydroxy-1-(4methylsulfonylphenyl)propan-2-yl]acetamide. Lu et al., (2015) discuss the acute toxicity of the pharmaceuticals, Florflenicol (FF) and Thiamphenicol (TAP) and their intermediates, an issue previously seldom addressed. The researchers experimented on the effects of the antibiotics on the marine bacterium Vibrio fischeri. The experiment revealed that acute toxicity was slightly increased as a result of the production of the drugs intermediates. This combined of effect of parent drug and products generated during degradation was also observed in other studies Bonnemoy et al., 2004; Zhu et al., 2014. The inhibition rate, the measure of the pharmaceuticals toxicity in this case decreased eventually after 60 minutes of the reaction considerably but not substantially below the initial toxicity. The toxicity of FF and TAP was also observed on several species of algae by Lai et al., (2009) and resulted in conclusive evidence to suggest the drugs retarded the growth of the aquatic organisms though in varying degrees.

\section{Primidone:-}

Wastewater in many water scarce countries is being reclaimed and used to augment the lack of access to freshwater in areas of the economy such as agriculture. In those instances treated waste water is used to for irrigation of farmlands as seen in countries such as China where established guidelines for the quality of reclaimed water (US EPA, 1992; Chang et al., 1996) do not always consider trace pollutants such a pharmaceuticals and EDCs. As a result the release of these pollutants into the environment has been continuous without a clear understanding of the ecological and health risk associated to their accumulation. The United States Geological Survey has reported the presence of PPCPs in surface and sub terrain waters that are influenced by wastewater in a 2002 nationwide study of emerging pollutants in water. The study found that $80 \%$ of the sites investigated tested positive for pharmaceutical compounds (US EPA, 1992; Koplin et al., 2002). Chen et al., (2011) A survey of 43 EDCs and PPCPs in Hebei, China revealed that nine (9) including Primidone was detected in soils irrigated by wastewater. Primidone is increasingly being considered as a good indicator for wastewater influence in surface and groundwater systemsGuo and Krasner, (2009).

Primidone is commonly used as antiepileptic drug with an empirical formula of $\mathrm{C}_{12} \mathrm{H}_{14} \mathrm{~N}_{2} \mathrm{O}_{2}$ and corresponds chemically to 5-ethyldihydro 5-phenyl-4,6(1-H,5H) pyrimidine-dione and has a molecular weight of 218.25.It is metabolized in the livers of animals to form two main metabolites; phenylethylmalonamide (PEMA) and phenobarbital (El-Masri and Portier, 1998). The chemical compound was introduced in clinical use in the 1950 and its metabolite, phenobarbital as early as 1912. Primidone passes through the human system usually $65 \%$ unchanged and is released into the environment commonly as urine through wastewater treatment plants. There have been numerous investigations which indicate the occurrence of primidone in surface and groundwater. An investigation by Drewes et al., identified the antiepileptic drugs carbamazepine and primidone as the most dominant in well treated effluents on North American and European treatment plants. Pharmaceutical often finds its way into aquifers and other sub terrain water systems when "treated" effluent is used for irrigation and aquifer recharge in countries 
where the commodity is scarce. Outdated practices in the early parts of this century saw much of the developed world treating wastewater by applying it to agricultural lands. Even though over time percolation did treat the wastewater to some extent, organic pollutants persistent in nature found themselves into groundwater systems and eventually drinking water throughout Berlin (Ginzel et al., 1995). Primidone was among the list of psychotic compounds detected in aquifers that are situated below former agriculture/sewage farms. In other instances ground water becomes contaminated by personal care products and pharmaceuticals by landfill leachates (Linde, 1992; Herberer and Stan, 1997; Peschka et al., 2006; Massmann et al., 2008b; Richter et al., 2008b; Hass et al., 2012a) and as farm run offs as these compounds are applied as medicine to farm animals or in the form of pesticides and feed additives.

\section{Advanced Oxidation Processes:-}

Advanced oxidation processes (AOPs) refer to a group of chemical-oxidative methods that have the ability to produce powerful hydroxyl radicals. In this section the processes ozonation, Fenton's Reagent, heterogeneous photo catalysis, ultra-sonic irradiation along with oxidants such a hydrogen peroxide, calcium peroxide will be reviewed as methods used to remove emerging contaminants from water based matrices. Conventional wastewater treatment plants are designed to remove contaminants such as biocidal and or non-biodegradable chemicals, solids and pathogens through chemical and physical processes. Advances over the decades in water treatment technologies have improved physical and chemical processes to adequately remove organic compound that may be dispersed in solution to even combat chemical compounds in trace quantities that were not once considered hazardous, the chemical processes are mostly oxidative chemical processes. Membrane technology, adsorption have also been technically broadened to challenge emerging contaminants. Engineers are now looking towards advanced oxidation processes as a necessary component to the water treatment process if the threat or the fear of the unknown long term impacts of PPCPs may have on humans and the environment. AOPs have been known to improve overall removal efficiencies of contaminants and was previously used as to attain the highest quality of treated water. Advanced oxidation treatment technologies are broadly defined as aqueous phase oxidation methods that are based on the generation of intermediaries of free radicals (Comninellis et al., 2008). Despite the high performance quality and efficiency of these methods be it the use of chemical oxidants such ozone, $\mathrm{H}_{2} \mathrm{O}_{2}$, metal catalysts, $\mathrm{CaO}$ or a combination of the aforementioned and energy. It is important to note that AOPs are used as enhancers in water treatment rather than a complete replacement of the conventional methods. Photooxidation can be largely considered as the inducing of oxidation by the use of light which commonly occurs by the loss of electrons from a species as a result of photoexcitation or the reaction of other chemical compounds by light. The principle is among the leading degeneration process and happens when organic materials are exposed to air and light (Sai et al., 2014). Chemical oxidation involves the use of oxidants to aqueous waste steams to convert organic pollutants to $\mathrm{CO}_{2}$ and $\mathrm{H}_{2} \mathrm{O}$ and can be made more efficient if oxidants are applied to waste streams in the presence of UV light. Direct use of oxygen as the oxidizing agent on organic compounds is not practiced as it requires high energy and has a very slow reaction time. In many applications of photo chemical oxidation, hydrogen peroxide, ozone are used as the photoactive oxidants for effective and safe degeneration of contaminants. Fluorine, a known oxidant, despite its high potential is not used during water treatment because of its high toxicity.

\section{Ozonation:-}

Ozonation or ozonisation is the inclusion of Ozone $\left(\mathrm{O}_{3}\right)$ into water to produce reactive oxygen species which are capable to degrade a wide range of organic compounds and microorganisms (Rice and Netzer, 1982; Masschelein, 1991;Langlais et al., 1991).

Ozone is prepared by applying energy to oxygen and because of its relative instability is usually generated on site of the treatment plant for immediate use. Exposure to water allows ozone to undergo a decomposition similar to other chemical oxidants to form intermediaries, free radical, which are more powerful in oxidizing (Wang et al., 2004). The combination of Ozone and UV has been technically broaden throughout the years and is even more widely used to remove a wide range of pollutant from water. The degradation of pollutants usually occur directly by ozone or by the radicals it produced during rapid decomposition though the radicals are much more potent (Munter, 2001). This known oxidative ability of ozone and radical generation, makes it among the most widely tested advance processes in research for its capacity and efficiency in removing more persisting compound and pharmaceuticals. Quinones et al., 2015, demonstrated the degradation rate of emerging compounds by ozonation and a combined system of photocatalytic oxidation. The experiment showed the emerging contaminants, acetaminophen, antipyrine, biphenol A, caffeine, metoprolol, and testosterone, to be readily degraded by ozone. Authors, Camel and Bernard give a comprehensive review of the main uses of the oxidation process in treatment of surface and groundwater for consumption (Camel and Bernard, 1998). 


\section{Hydrogen Peroxide:-}

Hydrogen peroxide is a naturally occurring metabolite of many organisms which usually decomposes to form oxygen and water. It is also produced naturally when sunlight interacts with water in the environment. Industrially $\mathrm{H}_{2} \mathrm{O}_{2}$ is manufactured by the anthraquinone process developed by BASF. The application of the peroxide is numerous. According to Hage et al., 2005, approximately $60 \%$ of hydrogen peroxide produced is used in the paper manufacturing industry and it is generally seen as a safe antimicrobial agent and is used in many developing countries for wound treatment (Rahman et al., 2010; Velding et al., 2014). The chemical compound has been studied in combination with UV radiation as an effective method in treating water that has been contaminated by various emerging pollutant that usually go about undetected. This natural occurring combination is among the most powerful photo degradation methods for pollutant removal. It has been used to treat easily oxidized contaminants and much harder oxidized ones such as hydrocarbons and pesticides (Metz et al., 2011a; Metz et al., 2011b).

The application of hydrogen peroxide as a photo oxidant has a number of benefits such as its thermal stability, availability and its ability to be stored on site. The oxidant is able to generate two hydroxyl compounds per molecule as shown in equation 1 (Lengrini et al., 1993; Mandal et al., 2004).

$$
\mathrm{H}_{2} \mathrm{O}_{2} \rightarrow 2 \mathrm{HO} \text { (eq 1) }
$$

The use of hydrogen peroxide and UV has been the more conventional advanced oxidation processes along with ozone. The use of this process to remove contaminants have been well documented throughout the literature.

\section{Calcium Peroxide:-}

Though hydrogen peroxide is commonly used to provide oxygen there are a few disadvantage to its used, some of which were outlined by Cassidy and Irvine, (1999). One such disadvantage includes its rapid and uncontrollable release of oxygen. Solid oxygen sources such as calcium peroxide has been found to release oxygen much slower than direct application of $\mathrm{H}_{2} \mathrm{O}_{2}$. The oxidative properties of calcium/ magnesium peroxide have exhibited promising degradative potential for the controlled decontamination of soil polluted with pollutants such as hydrocarbons (Bogan et al., 2003; Ndjou' ou and Cassidy, 2006).

Calcium peroxide is a powerful oxidizer and was investigated to be a potentially efficient oxidizer than the other versatile metabolite, $\mathrm{H}_{2} \mathrm{O}_{2}$ (Northup and Cassidy, 2008). The efficiency of $\mathrm{CaO}_{2}$ was demonstrated by researchers to degrade tetracloroethylene $\left(\mathrm{C}_{2} \mathrm{C}_{14}\right)$ and 2, 4, 6- trinitrotoluene (Arienzo, 2000). Calcium peroxide described by Ma et al., 2007 as a white/yellowish solid peroxide with a high energy covalent bond is made by the addition of hydrogen peroxide to calcium hydroxide and then dried to produce a solid.

$$
\mathrm{Ca}(\mathrm{OH})_{2}+\mathrm{H}_{2} \mathrm{O}_{2} \rightarrow \mathrm{CaO}+2 \mathrm{H}_{2} \mathrm{O} \text { (eq. 2) }
$$

The use of Calcium peroxide as an oxidative agent in waste activated sludge of persistent compounds was investigated by Zhang et al., 2015. The scientists concluded that the release of $\mathrm{OH}$ radicals were the dominant forces of degradation. In other studies the solid peroxide is used to treat contaminated soil and groundwater (Goi et al., 2011; Xu et al., 2011).The use of Calcium peroxide and UV as a single treatment process is currently being studied to remove emerging pollutants, Primidone, Cabamazepine, Florfenicol and Thiamphenicol from water on a lab scale by the authors of this review.

\section{Fenton Reagent:-}

Fenton's reagent $\left(\mathrm{H}_{2} \mathrm{O}_{2} / \mathrm{Fe}^{2+}\right.$ or $\left.\mathrm{Fe}^{3+}\right)$ is an advanced chemical oxidation process used in water treatment. It was discovered by Henry John Horstman Fenton in 1984, (Fenton, 1984) and is acknowledged to be an excellent technology in removing pollutants from waste water efficiently and safely (Lee et al., 2008; Wang et al., 2008). The basis of Fenton's reaction is the production of powerful oxidants; radical species, when ferrous salt and hydrogen peroxide are combined. The ferrous iron $\left(\mathrm{Fe}^{++}\right)$generates hydroxyl radical $(\cdot \mathrm{OH})$ by catalyzing $\mathrm{H}_{2} \mathrm{O}_{2}$ as depicted in (equations 3-7).

$$
\begin{aligned}
& \mathrm{H}_{2} \mathrm{O}_{2}+\mathrm{Fe}^{2+} \rightarrow \cdot \mathrm{OH}+\mathrm{OH}^{-}+\mathrm{Fe}^{++} \\
& \mathrm{OH}+\mathrm{RH} \rightarrow \cdot \mathrm{R}+\mathrm{H}_{2} \mathrm{O} \\
& \mathrm{R}+\mathrm{Fe}^{3+} \rightarrow \mathrm{R}^{+}+\mathrm{Fe}^{2+} \\
& \mathrm{Fe}^{2+}+\cdot \mathrm{OH}^{-} \rightarrow \mathrm{Fe}^{3+}+\mathrm{OH}^{-} \\
& \mathrm{OH}+\mathrm{H}_{2} \mathrm{O}_{2} \rightarrow \mathrm{HO}_{2}+\mathrm{H}_{2} \mathrm{O}
\end{aligned}
$$


Fenton's reagents have been paired with UV irradiation and found to be more efficient in the degradation of pollutant in solution (Ruppert et al., 1993; Pignatello et al., 1994). This pairing is referred to as photo-Fenton reaction or photo assisted Fenton Reaction. 'Dark' Fenton reaction as referred to by, to imply the application of the Fenton's reagent in the absence of irradiation for removal of contaminants, has a disadvantage in that the oxidation process is slowed down as the $\mathrm{Fe}+2$ is converted to $\mathrm{Fe}+3$ (equation 8).

$\mathrm{Fe}^{2+}+\mathrm{H}_{2} \mathrm{O}_{2} \rightarrow \mathrm{Fe}^{3+}+\mathrm{HO}^{-}+\mathrm{HO}$ (eq. 8)

The Fenton Oxidation processes has been exploited for its efficiency in a number of ways since its discovery for degrading organic and some inorganic pollutants. Ma and Zhou, (2009) used the process to reduce organic pollutant in leachate at a landfill site (Ma and Zhou, 2009). The technique has was demonstrated by Rashed et al., 2004, to degrade phenol and formaldehyde in different water matrices. The oxidative process has an overall disadvantage in that its sensitivity to $\mathrm{pH}$ change above 4 results in precipitation of ferric hydroxides.

\section{Heterogeneous Photocataysis:-}

Heterogeneous photocatalysis may be defined as the assistance of photoreaction process by a catalyst. This advance process has been applied in the purification of air and water containing persistent organic and inorganic compounds and can be traced back traced back to the 1970s when Fujishima and Honda discovered. One of the most widely used and highly effective catalysts is $\mathrm{TiO} 2$ because of its high potential to oxidize organic and inorganic compounds from solution via redox processes. The metal catalyst is also very stable chemically, nontoxic and relatively affordable. Cesaro et al., described the mechanism of heterogeneous photocatalysis as the transfer of electrons from the valence to the conduction band as a result of light irradiation. Electrons (e-) and positive charges or holes $(\mathrm{H}+)$ are generated. Both these charge carriers are strong oxidants are therefore able to oxidize $\mathrm{H}_{2} \mathrm{O}_{2}$ molecule to form hydroxyl radicals (equation 9). Holes can also directly oxidize organics as summarized by equation 10. Photocatalyst such as $\mathrm{TiO} 2$ basically hones UV energy to breakdown contaminants.

$$
\begin{aligned}
& \mathrm{H}++\mathrm{H} 2 \mathrm{O} \rightarrow . \mathrm{OH}+\mathrm{H}^{+} \quad \text { (Eq. 9) } \\
& \mathrm{H}++ \text { organic } \rightarrow \text { organic }+\quad \text { (Eq. 10) }
\end{aligned}
$$

Heterogeneous photocatalysis is considered one of the newest advanced oxidation processes and therefore its full scale application is not wide spread due to its technical and economic associations. There have however been increasing scientific work geared towards improving the efficiency of this particular AOP over the years for water treatment. Borges et al., investigated the use of heterogeneous photocatalysis on the removal of emerging pollutants, paracetamol as the model molecule. The authors concluded that $\mathrm{TiO} 2$ resulted in photocatalytic activity for removing the compound from waste water. Forty two per cent of the EC was removed after 8 hours of exposure (Borges et al., 2015) 


\section{Ultrasonic Irradiation:-}

Another advanced oxidation process being exploited and studied for increase efficiency and economical large scale application for removing emerging contaminants from wastewater streams is Ultrasonic Irradiation. The fascination with the catalytic effect of high energy frequencies $(15 \mathrm{KHz}-1 \mathrm{MHz})$ started in 1927 when Richards and Loomis reported on the chemical transformation ultrasound effected. But what are the underlying principles of this technique? Ultrasonic irradiation results in in multiple reaction pathways during the degradation of pollutants. These pathways include, pyrolysis, hydroxyl radical reactions (Thompson and Doraiswassy 2000). When applied to liquid an event called electohydraulic cavitation occurs. This cavitation goes through a series of events which ends with the implosion of microbubbles which then releases large amount of energy (Gogate, 2002). This extreme change in conditions results in direct or indirect chemical alterations.

There have been a number of work which attempted to use the oxidative process in removing emerging contaminants, such as pharmaceuticals from solution. Hoffman et al., demonstrated the efficiency of sonochemical for the degradation pf p-nitrophenol, carbon tetrachloride, parathion, p-nitrphenyl acetate and trinitrotoluene. The study concluded that the method is effective for the rapid destruction of the organic compounds due to the extreme temperature and pressure and formation of powerful hydroxyl radicals (Hoffman et al., 1996)

\section{Comparison:-}

Advanced oxidation processes are grouped on the basis of their aqueous phase oxidation mechanism that results in hydroxyl radicals which then breaks down pollutant into biodegradable intermediaries or completely. An important commonality and drawback to among AOPs is the relatively high cost of reagents and high cost of energy as may be the case with energy intensive processes such as sonochemical irradiation and photocatalytic methods, especially when compared to biological- primary and secondary techniques. The treatment however do have for the most part their individual advantages and disadvantages, some of which will be discussed in this section.

So far the use of AOPs to optimize the removal of pollutants; microorganisms and inorganic micro-pollutants, has proven successful and is used especially in cases where treated water is to meet the highest grade, usually for consumption. Advanced oxidation process have been increasingly being used in streams that have concentrations of ECs and or an assortment of their metabolites. There are a number of challenges AOPs faced on large scale removal of contaminants. Challenges such as matrix composition- natural organic matter, dissolved and suspended solids, temperature and $\mathrm{pH}$ (Oppenlander, 2003). These parameters may have restricting effect on the type of AOP used and its efficiency. The Fenton reaction as discussed in earlier sections is very $\mathrm{pH}$ specific and is debilitated by conditions above the $\mathrm{pH}$ of 4 since iron, an important limiting factor is precipitated as the $\mathrm{pH}$ increases. Degradation rates of pollutant is increased when Fe (II) ion is in high concentration. Ultra-violet irradiation aided processes such as $\mathrm{UV} / \mathrm{H} 2 \mathrm{O} 2, \mathrm{UV} / \mathrm{CaO} 2, \mathrm{UV} / \mathrm{Fenton}$ and heterogeneous photolysis depend on UV transmittance (UVT). The processes efficiency can be hampered significantly if the UVT is not optimum. One of the main disadvantages of $U V / \mathrm{H}_{2} \mathrm{O}_{2}$ processes as explained by Naddeo et al., is the small molar extinction coefficient of hydrogen peroxide and the strong dependence of photolysis on the pH conditions of the media (Andreozzi et al., 1999).

The mechanism of generating free radicals is what primarily distinguishes AOPs from other treatment methods. Photocatalyst is the term used to refer to UV or solar aided AOP processes and is often used to optimize the degradation process. In instances where natural solar energy is not used, energy consumption maybe lead to high energy cost. Esplugas et al., presented an energy cost evaluation of UV/H2O2, O3 and Fenton and estimates for reagents used in his experiment. The costs were calculated based on the degradation of phenol at two intervals. From the authors estimate, photocatalysts and UV were notably more expensive than the other AOPs evaluated. Sonolysis or ultra-sonar irradiation's major disadvantage is its energy consumption as well and also its limited use for large volume (Naddeo et al., 2013). The processes especially when paired with other methods can be effective in degrading micro pollutants and may reduce cost (Naddeo et al., 2009; De bel et al., 2009; Landi et al., 2010)

\section{Conclusion:-}

Advanced oxidation process are not intended in any way to replace the conventional water and waste water treatment processes but instead to augment some of the shortfalls and to improve the efficiency of water works. AOPs have a unique ability to remove emerging pollutants by powerful oxidants and can be made economical depending on the methods applied. This versatility continues to allow scientists to improve upon exiting knowledge to discover more affordable but effective combinations. Emerging pollutants are an increasing problem in a growing world where water security is crucial to economies and growth. The study of the effect of emerging pollutants are 
lacking and therefore provides a myriad of opportunity for future research in terms of identification of new pollutants, their effects and development of economical but effective treatment processes. Advanced oxidation process provides a promising solution to offset the likely effects of emerging contaminants on environment.

\section{Reference:-}

1. Adewuyi YG. Sonochemistry: Environmental Science and Engineering Applications. Ind. Eng. Chem. Res.2001; 40: 4681-4715.

2. Andreozzi R, Caprio V, Insola A, Marotta R. Advanced oxidation processes (AOP) for water purification and recovery. Catalysis Today 1999; 53: 51- 59

3. Andreozzi R, Marotta R, Pinto G, Pollio A. Carbamazepine in water: persistence in the environment, ozonation treatment and preliminary assessment on algal toxicity. Water Research 2002; 36: 2869-2877

4. Barcelo D. Emerging pollutants in water analysis. Trends Anal. Chem 2003; 22: 14-16

5. Barr L, Metaxas G, Harbach C, Savoy L, Darbre, P. Measurement of paraben concentrations in human breast tissue at serial locations across the breast from axilla to sternum. J. Appl. Toxicol 2012; 32(3): 219-232

6. Bogan B. W, Trbovic V, Paterek J.R. Inclusion of vegetable oils in Fenton's chemistry for the remediation of PAHcontaminated soils. Chemosphere 2003; 50:12-21.

7. Bolang N, Ismail A.F, Salim M.R, Matsuura T. A review of the effects of emerging contaminants in wastewater and options for their removal. Deasalination 2009; 239: 229-246.

8. Borges EM, Garcia MD, Hernandez T, Ruiz-Morales JC, Esparza P. Supported Photocatalyst for Removal of Emerging Contaminants from Wastewater in a Continuous Packed-Bed Photoreactor Configuration. Catalysts 2015; 5: 77-87

9. Campbell CG, Borglin SE, Green FB, Grason A, Wozei E, StringfellowWT. Biologically directed environmental monitoring, fate, and transport of estrogenic endocrine disrupting compounds in water: A review. Chemosphere 2006; 65: $1265-80$

10. Cesaro A, Naddeo V, Belgiorno V. Wastewater Treatment by Combination of Advanced Oxidation Processes and Conventional Biological Systems. J BioremedBiodeg 2013; 4: 208.

11. Chand R,Bremner DH, Namkung KC, Collier PJ, Gogate PR. Water disinfection using the novel approach of ozone and a liquid whistle reactor. Biochemical Engineering Journal 2007; 35: 357-364

12. Chang H.S, Chao K.H et al. The method of identification, analysis, and removal of endocrine disrupting compounds (EDCs) in water. Hazard Mat 2009; 172: 1-12.

13. Comninellis C, Kapalka A, Malato S, Parsons S.A, Mantzavinos D. Advanced oxidation processes for water treatment: advances and trends for R\&D. Chem. Technol. Biotechnol 2008; 83: 769-776

14. Czech B, Rubinowska K. TiO2- assisted photocatalytic degradation of diclofenac, metoprolol, estrone and chloramphenicol as endocrine disruptors in water. Adsorption 2013; 19:619-630.

15. Daneshvar, N., Behnajady, M.A., Mohammadi, M.K.A., and Dorraji, M.S.S. UV/H2O2 treatment of Rhodamine B in aqueous solution: Influence of operational parameters and kinetic modeling. Desalination 2008; 230: 16.

16. De Bel E, Dewulf J, Witte BD, Van Langenhove $\mathrm{H}$, Janssen C. Influence of $\mathrm{pH}$ on the sonolysis of ciprofloxacin: Biodegradability, ecotoxicity and antibiotic activity of its degradation products. Chemosphere 2009; 77: 291-295

17. Ernst, M., Jekel, M., 1999. Advanced treatment combination for groundwater recharge of municipal wastewater by nanofiltration and ozonation. 277-84

18. Fatta-Kassinos D, Meric S, Nikolaou A. Pharmaceutical residues in environmental waters and wastewater: current state of knowledge and future research. Anal. Bioanal. Chem 2011; 399: 251-275

19. Goi A, Viisimaa M, Trapido $M$ et al. Polychlorinated biphenyls- containing electrical insulating oil contaminated soil treatment with calcium and magnesium peroxides. Chemopshere 2011; 82: 1196-1201

20. Harvey P, Everett, D. Parabens detection in different zones of the human breast: Consideration of source and implications of findings. J. Appl. Toxicol 2012; 32(5): 305-309.

21. Hayes TB, Haston K, Tsui M, Hoang A, Haeffele C, VonkA.Feminization of male frogs in the wild: water-borne herbicide threatens amphibian populations in parts of the United States. Nature 2002; 419:895

22. Hoffmann RM, Hua I, Hochemer R. Application of ultrasonic irradiation for the degradation of chemical contaminants in water. UltrasonicsSonochemistry 1996; 3: 163-172

23. Jasper J.T, Sedlal D.L. Phototransformation of wastewater derived trace organic contaminants in open water unit process treatment wetlands. EnviSci and Technol 2013; 47: 10781-10790

24. Kao C. M, Chen S. C, Wang J. Y et al. Remediation of PCE- contaminated aquifer by an in situ two layer biobarrier: laboratory batch and column studies. Water Research 2003; 37: 27-38

25. Landi M, Naddeo V, Belgiorno V. Influence of ultrasound on phenol removal by adsorption on granular activated carbon. Desalination and Water Treatment 2010; 23: 181-186. 
26. Lee H, Shoda M. Removal of COD and color from livestock wastewater by the Fenton method. J. Hazard. Mater 2008; 153(3): 1314-1319.

27. Li Y, Wang J, Zhang A, wang L. Enhancing the quantity and quality of short chain fatty acids production from waste activated sludge using $\mathrm{CaO} 2$ as an additive. Water Reseach 2015; 83: 84-93.

28. Liu N, Sijak S, Zheng M et al. Aquatic photolysis of Florfenicol and thiamphenicol under direct UV iiradiation, UV/H2O2 and UV/Fe (ii) processes. ChemEng 2015; 260:826-834.

29. Liu Z, Kanjo Y, Mizutani S. Removal mechanism for endocrine disrupting compounds (EDCs) in waste water treatment-physical means, biodegradation, and chemical advanced oxidation: A review. Sci Total environ 2009; 407: 731-748

30. Ma Y, Zhang B, Zhao L et al. Study on the generation mechanism of reactive oxygen species on the calcium peroxide by chemiluminescence and UV-visible spectra. Luminescence 2007; 22: 575-580.

31. Ma X, Zhou M. A comparative study of azo dye decolorization by electro-Fenton in two

32. common electrolytes. Chem Tech and Biotech 2009; 84 (10): 1544-1544.

33. Malato S, Maldonado MI, Fernández P, Oller I, Polo I. Decontamination of water by solar irradiation. 2014

34. Munter R. Advanced Oxidation Processes - current status and prospects. Proceedings Estonian Academy of Science (Series: Chemical) 2001; 50: 59-80

35. Naddeo V, Meriç S, Kassinos D, Belgiorno V, Guida M. Fate of pharmaceuticals in contaminated urban wastewater effluent under ultrasonic irradiation. Water Res 2009; 43: 4019-4027

36. Ndjou'ou A.C, Cassidy D. Surfactant production accompanying the modified Fenton's oxidation of hydrocarbons in soil. Chemosphere 2006; 65: 1610-1615.

37. Northup A, Cassidy A. Calcium peroxide ( $\mathrm{CaO} 2)$ for use in modified Fenton's chemistry. Hazard Mater. 2008; 152: 1167-70

38. Petovic M, Goonzalez S and Barcelo D. Analysis and removal of emerging contaminants in waste water and drinking water. Analytical Chem 2003; 12:685-696

39. Pignatello J, Chapa G. Degradation of PCBs by ferric ion, hydrogen peroxide and W light. Environ. Toxicol. Chem 1994; 13: 423-427.

40. Rahman, GA, Adigun, I. A; Yusuf, I. F, Ofoegbu, C.K.P. Wound dressing where there is limitation of choice. Nigerian Journal of Surgical Research 2010; 8:3-4

41. Rashed, I. G, Hanna, M. A., El-Gamal, H. F., Al-Sarawy, A. A. and Wali, F. K. M. Application of Chemical Oxidation Technology for Treating Industrial Wastewater Containing High Concentrations of Phenol, J. for Environ. Sci. 2004; 2:15-30.

42. Rosal R, Rodriguez A, Gonzalo MS, Garcia-Calvo E. Catalytic ozonation of naproxen and carbamazepine on titanium dioxide. Applied Catalysis B-Environmental 2008; 84: 48-57

43. Ruppert G, Batter R.The photo-Fenton reaction - an effective photochemical wastewater treatment process, J. Photochem. Photobiol. A: Chem 1993: 73: 75-78.

44. Samir K.K, Xie B, Thompson ML, Sung SW, Ong SK, LeeuventJV.Fate, transport, and biodegradation of natural estrogens in the environment and engineered systems. Environ SciTechnol 2006; 40: 6537-46.

45. Shi H, Cheng X, Wu Q, Mu R, Ma Y. Assessment and Removal of Emerging Water Contaminants. J Environ Anal Toxicol 2012; S2:003

46. Sijak S, Liu N, Zheng M et al. Degradation of Anti Convulsant drug Primidone in aqueous solution by UV Photooxidation Processes. Environ EngSci 2015: 32:435-444.

47. Et al., 2003 UN WWAP. Water for people, water for life (2003): 3rd world water forum in Kyoto, Japan. www.norman-network.net.

48. Velding, K.; Klis, S.-A., Abass, K. M, Tuah, W.; Stienstra, Y., van der Werf, T. Wound Care in Buruli Ulcer Disease in Ghana and Benin. American Journal of Tropical Medicine and Hygiene 2014; 91 (2): 313-318.

49. Vinu R, Madras G. Environmental remediation by photocatalysis. Journal of the Indian Institute of Science 2010; 90: 198-230.

50. Vogna D, Marotta R,Andreozzi R, Napolitano A, d'Ischia M. Kinetic and chemical assessment of the UV/H2O2 treatment of antiepileptic drug carbamazepine. Chemosphere 2004; 54: 497-505

51. Vogna D, Marotta R, Napolitano A, Andreozzi R, d'IschiaM.Advanced oxidation of the pharmaceutical drug diclofenac with UV/H2O2 and ozone. Water Research 2004; 38: 414-422

52. Wang S. A Comparative study of Fenton and Fenton-like reaction kinetics in decolourisation of wastewater. Dyes Pigment 2008; 76(3): 714-720.

53. Y. Huang, D.L. Twidwell and J.C. Elrod, Occurrence and effects of endocrine disrupting chemicals in the environment, Practice Periodical of Hazardous, Toxic and Radioactive Waste Management ASCE, 2003; 7:241-252

54. Zhang A, Wang J, Li Y. Performance of calcium peroxide for the removal of endocrine-disrupting compounds in waste activated sludge solubilization. Water research 2015; 71: 125-139. 